\title{
INTRODUCCIÓN: A LOS 50 AÑOS DE LA LEY GENERAL DE EDUCACIÓN DE 1970
}

\section{Introduction: 50 years after the General Education Act of 1970}

\section{Juan Manuel Fernández-Soria ${ }^{\alpha}$ y Diego Sevilla Merino ${ }^{\beta}$}

La fuerza evocadora de los números redondos suele ser una razón, aunque circunstancial, para recordar un acontecimiento. La magia de las cifras contundentes -en este caso medio siglo- invita a volver la mirada hacia el suceso rememorado. Esta es la razón inicial que impulsa esta revisitación de la Ley General de Educación (LGE) que añade, aprovechando ese originario empuje, un motivo menos accidental, más básico y, quizá, necesario: seguir indagando, con nuevos análisis y miradas novedosas, en lo que la LGE supuso para la modernización del país. Así, nos mueve, sobre todo, la voluntad de aportar nuevos elementos de investigación sobre una ley que, para muchos, entre ellos los redactores de la Ley de Ordenación General del Sistema Educativo (LOGSE) que vino a sustituir a la LGE, fue, hasta ese momento, «la de mayor importancia tras la Ley Moyano, de 1857»; e, indudablemente, un «acontecimiento notorio» que produjo «un proceso de modernización y normalización en el discurso oficial» español. ${ }^{2}$

En la presentación al número extraordinario que la Revista de Educación le dedicó a la Ley a los veinte años de su aprobación, su entonces director afirmaba algo que muchos comparten y que motiva este monográfico de la revista Historia y Memoria de la Educación: que la LGE

\footnotetext{
^ Departamento de Educación Comparada e Historia de la Educación (Facultad de Filosofía y Ciencias de la Educación). Universidad de Valencia. Avenida de Blasco Ibáñez, n. ${ }^{\circ}$ 30. 46010-Valencia, España. Juan.M.Fernandez@uv.es (1) https://orcid.org/0000-0002-1274-0482

B Departamento de Pedagogía (Facultad de Ciencias de la Educación). Universidad de Granada. Campus Universitario de Cartuja. 18071-Granada, España. sevilla@ugr.es

1 Ministerio de Educación y Ciencia, Libro Blanco para la Reforma del Sistema Educativo (Madrid: MEC, 1989): 13.

2 José Gimeno Sacristán, La educación que he vivido, por la que trabajo y sigo comprometido. Discurso del nuevo Doctor Honoris Causa Don José Gimeno Sacristán. (Málaga: Universidad de Málaga, 2011), s.p., (p. 5).
} 
"supuso un intento de modernización del sistema educativo español, inserto en un proceso modernizador del aparato productivo y del cuerpo social y favorecido por la situación internacional». ${ }^{3}$ Alejandro Tiana, al tiempo que señala el objetivo de aquel monográfico -proporcionar «elementos para una revisión»- confía en que «en el próximo futuro se alcen nuevas voces para continuar el análisis aquí iniciado», que "presenten perspectivas diferentes a las ahora mantenidas». ${ }^{4}$ Aunque no pretendemos continuar lo que hace treinta años inició la Revista de Educación, sí es intención de este monográfico, ahora que se cumplen cincuenta años de la promulgación de la LGE, ofrecer otras perspectivas de análisis que contribuyan con nuevos enfoques a su estudio y comprensión e indagar en lo que supuso para la modernización de España.

En este sentido, llama la atención la coincidencia de opiniones favorables a lo que la Ley entrañó. Desde el parecer lógicamente propicio del ministro que la firma aseverando que es «una ley que da respuesta a las necesidades objetivas de un auténtico desarrollo», 5 hasta quien auguraba para Villar Palasí un lugar en la historia como lo tuvieron Moyano y Fernando de los Ríos, ${ }^{6}$ pasando por el tímido y confuso reconocimiento que concita entre quienes ven en ella el inicio del deterioro de nuestro sistema educativo; sería este el caso de Sánchez Tortosa, quien, al tiempo que tilda a la LGE de ambigua "reforma esquizofrénica» que anticipa el modelo de la «escuela basura», afirma, aunque sin intención de elogiarla, que la LGE supuso en educación «el salto»-que no «abismo»- entre la educación franquista o preconstitucional y la educación democrática o constitucional. ${ }^{7}$ Lo que remite a la idea de la LGE como «transición»

\footnotetext{
3 Alejandro Tiana Ferrer, «La Ley General de Educación, veinte años después. Elementos para una revisión», Revista de Educación n. ${ }^{\circ}$ ext. «La Ley General de Educación veinte años después» (1992): 9.

4 Tiana, «La Ley General de Educación», 10.

5 José Luis Villar Palasí, «Discurso del ministro de Educación y Ciencia informando a la Comisión de Educación de las Cortes sobre la aplicación de la Ley General de Educación», Boletín oficial de las Cortes Españolas. Diario de las sesiones de comisiones. Comisión de Educación y Ciencia. Apéndice núm. 10 (14 febrero 1972), 3.

6 Ignacio Fernández de Castro, Reforma educativa y desarrollo capitalista. Informe crítico de la Ley de Educación (Madrid: EDICUSA, 1973), 9.

7 José Sánchez Tortosa, El culto pedagógico. Crítica del populismo educativo (Madrid: Ediciones Akal, 2018), 365-366.
} 
entre uno y otro tipo de educación, razón esta que también estimuló nuestro interés por revisitar la Ley General de Educación.

En efecto, hay quien sostiene que esta ley inicia la transición educativa en España años antes de que lo hiciera la transición política e histórica en 1975 con la muerte del dictador. ${ }^{8}$ Pero ¿realmente supuso eso la LGE?; ¿representa el paso de la educación franquista a la educación democrática?; ¿fue una fase intermedia entre una educación «anticuada» y otra "moderna», el tránsito de una educación desfasada a otra anclada en su tiempo?; ¿significó el cambio de una educación a otra? Ricardo Díez Hochleitner, uno de sus más reconocidos impulsores, no duda en responder afirmativamente a estas cuestiones, proclamando que «la transición política española hubiera encontrado un caldo de cultivo para la justa crispación si la LGE de 1970 no hubiera contribuido tan directamente a la democratización del sistema educativo y a la igualdad de oportunidades, superando muchos de los clasismos antes existentes», y que el balance de sus logros hubiera sido incluso mayor al ya reconocido de no ser por los «esfuerzos involucionistas» que afectaron a su aplicación. ${ }^{9}$ En todo caso, responder a las preguntas recién planteadas requiere echar una mirada, por rápida que sea, a los precedentes de la Ley de 1970 y a sus principales propuestas, otra de las razones que nos empujan a revisitar esta ley.

Lo anterior quizá contribuya a explicar este nuevo acercamiento a la LGE de 1970. Sin duda nuevo, pero por distinto, porque la LGE ha sido ya objeto de numerosos estudios ${ }^{10}$ que presentan particularidades historiográficas notables. Los cincuenta años que median desde la aprobación de la Ley permiten destacar, en efecto, algunos rasgos significativos. Entre ellos el hecho de que la Ley se convierte en un momento bisagra, en un tiempo vierteaguas que los historiadores suelen utilizar

\footnotetext{
8 Así lo afirman, entre otros, Emiliano Martínez en el obituario «Ricardo Díez Hochleitner, un español universal» (El País, 2 de abril de 2020), y Blas Cabrera Montoya, «Políticas educativas en clave histórica: La LOGSE de 1990 frente a la LGE de 1970», Tempora 10 (2007): 161.

9 Ricardo Díez Hochleitner, «Ante la nueva reforma de la Educación». Entrevista. Plantel. Revista de la Escuela Universitaria del Profesorado de Ciudad Real 1(1989): 24.

10 Veinte años después de su aprobación, Inés Chamorro ya había compilado una extensa relación de publicaciones sobre la Ley (M. Inés Chamorro Fernández, «Bibliografía sobre la Ley General de Educación de 1970», Revista de Educación n. ${ }^{\circ}$ ext. "La Ley General de Educación veinte años después» (1992): 377-438).
} 
para situar cronológicamente sus estudios: unos llegan «hasta la Ley de 1970», otros parten "desde la LGE» ... De este modo, los historiadores están reconociendo que la LGE supuso un punto de inflexión, un antes y un después para la educación española y, lógicamente, para la investigación histórico-educativa. Naturalmente, la LGE es también contemplada en estudios más amplios que no pueden ignorar el jalón histórico que representó.

Pero en la producción científica sobre la LGE también es visible el cambio en los intereses temáticos de los historiadores de la educación. Aunque mostrarlo requeriría un estudio más extenso y preciso que el que aconsejan estas páginas de presentación, en el protagonismo de los temas objeto de estudio de la Ley se observa, en general, una evolución hacia las tendencias historiográficas actuales. Las muchas tesis doctorales, libros y artículos especializados que han elegido la LGE como objeto de estudio, han fijado su atención en una variedad de temas que evidencia tanto la atemporalidad de unos como la novedad de otros. Así, del estudio de la estructura educativa de la Ley (con atención especial a la educación básica y la formación profesional), del examen de los temas asociados a la escuela que, por su innovación o ausencia, fueron motivos de preocupación (como el papel del tutor, la programación de la enseñanza, la participación escolar o la ruralidad escolar), del análisis de los actores escolares (con especial dedicación a la inspección, la dirección escolar y, por supuesto, la formación de los maestros), se ha pasado a la investigación de otros asuntos más innovadores y al tratamiento más novedoso de algunos de los temas antes citados, que muestran el progreso de la historiografía en España. De esta suerte, cuestiones atemporales como la formación de maestros o la dirección escolar, han sido después abordadas examinando aspectos antes relegados o ignorados como las competencias profesionales o las diferencias de género en la formación docente, y entre los temas asociados a la escuela han preocupado el de la calidad de la enseñanza, el currículo y la evaluación, siquiera sea formando parte de estudios más amplios que recorren el tiempo de la LGE, o estableciendo comparaciones entre esta y las leyes orgánicas que le sucedieron, particularmente con la LOGSE.

Entre los temas novedosos de la LGE que han sido abordados de manera más fecunda, figuran los relativos al estudio de las disciplinas escolares, del currículo y de la cultura escolar, de la política educativa y del 
carácter transnacional de las influencias que recibe. Las disciplinas escolares y los libros de texto en la LGE han sido objeto de numerosas investigaciones que abarcan desde la conceptualización de las Ciencias Sociales (término que aparece por primera vez en la en la LGE), la educación literaria, la organización musical, la enseñanza de la Historia, de la Geografía, de la Religión, de la Educación Física, hasta el concepto de nación en la enseñanza de la Historia, la presencia de las nuevas tendencias historiográficas en los manuales escolares, y la didáctica de las Ciencias Naturales, de las Matemáticas, de las Ciencias Sociales, etc. Recientemente están surgiendo también investigaciones que ponen el foco de atención en la fotografía sobre la LGE como instrumento de propaganda del régimen franquista en su esfuerzo por transmitir una imagen nueva y moderna, ${ }^{11}$ de lo que este monográfico da también testimonio a través del artículo de Xisca Comas y Bernat Sureda «La Ley General de Educación de 1970 a través de las imágenes».

El tema de la política educativa y sus relaciones con el poder y la sociedad ha evolucionado desde el análisis y la evolución cuantitativista de los datos sobre centros, alumnos, profesores, puestos escolares, ratio profesor-alumno y escolarización en los distintos niveles educativos, hasta el estudio de la tramitación de la Ley y la oposición a la misma, al examen de los discursos pedagógicos, de la hegemonía y la legitimación, a la investigación de la ideología (tecnocrática, religiosa, económica...), a la investigación de los movimientos sociales y de la oposición a la política educativa franquista... Incluso, en un afán por ensayar una historia más global, la LGE ha sido también abordada en el contexto de la expansión industrial española y de las relaciones de la escuela con el entorno socioeconómico.

Con todo, el objeto de estudio más novedoso en el acercamiento al estudio de la LGE quizá sea el relativo a las influencias internacionales, tanto de países como de organismos supranacionales de carácter político, cultural o financiero, en el proceso de modernización educativa, enriqueciendo con importantes aportaciones el giro transnacional en la

\footnotetext{
11 La revista Historia y Memoria de la Educación se ocupó de este asunto en la parte monográfica del número 8 bajo el rótulo "Fotografía, Propaganda y educación”, en particular el trabajo de Sara González Gómez y Xavier Motilla Salas «Iconografía de la modernización educativa en España en el contexto de la Ley General de Educación de 1970», Historia y Memoria de la Educación 8 (2018): 449-487.
} 
historia de la educación española, aspecto este que cobra un especial protagonismo en este número de la revista Historia y Memoria de la Educación con artículos de Lorenzo Delgado Gómez-Escalonilla y Óscar Martín -«El apoyo internacional a la reforma educativa en España»- y de Mariano González-Delgado y Tamar Groves -«La UNESCO y la Ley General de Educación: la influencia de los organismos internacionales en torno a la modernización educativa en el franquismo»-.

Tradicionalmente, el estudio de la legislación escolar ha sido considerado un género menor en la historiografía educativa. Pero la sucinta relación de temas que acabamos de mencionar muestra que el estudio de la legislación escolar sigue siendo fundamental, y que lo decisivo es el modo de acercarse a ella. Con todo, somos conscientes de que la legislación, como un acto escolar, no ha gozado de buena fama en la historiografía de los hechos escolares, quizá por ser considerada irrelevante en una tendencia historiográfica proclive a las grandes narrativas y a los enfoques historiográficos suprarregionales y supranacionales, que prefieren los grandes planos globales de signo transnacional. Pero, como un acto escolar dinamizador y organizador de los demás actos escolares que regula, la legislación escolar habla, o informa, de la distribución del poder social, económico y político, y manifiesta, en cierto modo, la organización del orden social y la visión que tienen los poderes actuantes sobre los fundamentos sociales. Aunque esto es predicable especialmente para las constituciones de los Estados, también lo es para las normas legales que emanan de ellas, en particular las escolares, que regulan comportamientos no solo en el seno de la escuela sino también en el más amplio de la ciudadanía. ${ }^{12}$ Normas, disposiciones, actuaciones, procedimientos, actitudes, que, pensados para ser gestados en el ámbito de la escuela, lo trascienden para provocar en el cuerpo social usos y prácticas imperiosas para la modernización del país.

Muchos de los temas que la historiografía educativa refiere, se abordan con mayor profundidad en los escritos que componen la parte monográfica de este número de la revista Historia y Memoria de la Educación. En su diseño se han seguido tres criterios principales: por un lado,

12 Daniel Tröhler, «School Legislation, Mass Schooling, and Historiography», en Schoool Acts and the Rise of Mass Schooling, eds. J. Westberg, L. Boser y I. Brühwiler, (pp 349-372) (Palgrave: Macmillan, Cham, 2019), 352. 
estudiar la reforma de 1970 tanto desde una perspectiva amplia, casi panorámica, como desde otra que proyecte su foco de atención en objetos de estudio más concretos, yendo de lo macro a lo micro; por otro lado, también se ha pretendido visibilizar algunos de los nuevos planteamientos historiográficos; finalmente, hemos querido ofrecer estas páginas al testimonio de protagonistas directos de aquella reforma.

$\mathrm{Al}$ primer criterio responden dos de las aportaciones: «La Ley General de Educación de 1970, ¿una ley para modernización de España?» y «La Ley general de Educación y la pedagogía. Reencuentro y señal». El primero, de Juan Manuel Fernández Soria y Diego Sevilla Merino, planteado a modo de «vista aérea», señala algunas de las claves para examinar la LGE en clave modernizadora; sin perder de vista el concepto «modernización» en torno al cual pivota, indaga en los orígenes de la Ley, en su contexto, en sus ejes principales, en los obstáculos y resistencias a su puesta en marcha, en las controversias que provoca su recuerdo y el de sus creadores. Cerrando un poco más el ángulo de análisis, el trabajo de Alejandro Mayordomo Pérez, ofrece una amplia perspectiva histórica sobre los planteamientos pedagógicos que propone la Ley en la educación básica. En él se nos habla de innovaciones y del contexto en el que se plantean, de la inadecuación entre las propuestas pedagógicas, la realidad y la política necesaria para desarrollarlas.

Encogen más el foco de estudio Aurelio González Bertolín y Roberto Sanz Ponce, e Isabel Grana Gil. Los primeros, como anuncia el título de su artículo -«Villar Palasí: sobre tecnocracia y dirección escolar»- se detienen en examinar las circunstancias ideológicas y políticas concernientes tanto al propio ministro como a la educación del momento, incidiendo en uno de los aspectos más visibles de la reforma, su racionalidad tecnocrática, con orígenes en la polémica «España como problema»-«España sin problema». La discusión que rodeó la supresión del Cuerpo de Inspectores, un asunto escasamente atendido en nuestra historiografía educativa, es el otro eje de este artículo. Por su parte, Isabel Grana Gil, en su texto «La Ley General de Educación y la Iglesia: Encuentros y desencuentros», nos introduce en la postura de uno de los actores más señalados de la educación española de aquel tiempo, la Iglesia, y lo hace, por un lado, evidenciando la controversia entre la enseñanza estatal y privada y el debate generado en el seno de la Jerarquía eclesiástica sobre 
la gratuidad de la enseñanza recogida en la Ley, y, por otro lado, resaltando las alternativas a la Ley, con especial detenimiento en las propuestas por la Iglesia católica.

Al segundo criterio esgrimido -visibilizar nuevos planteamientos historiográficos en el estudio de la LGE-, responden los artículos de Lorenzo Delgado Gómez-Escalonilla y Óscar Martín García y el de Mariano González-Delgado y Tamar Groves. Los primeros, en su texto «El apoyo internacional a la reforma educativa en España», analizan el apoyo de organismos internacionales como la OCDE, la UNESCO, y también el Banco Mundial, la Fundación Ford y Estados Unidos, en el proceso de modernización educativa española dentro de los planteamientos occidentales de las teorías de la modernización y del capital humano. Por su parte, González-Delgado y Tamar Groves, en su texto «La UNESCO y la Ley General de Educación: la influencia de los organismos internacionales en torno a la modernización educativa en el franquismo", concretan el enfoque de su análisis en uno de esos organismos internacionales -la UNESCO- estudiando la importancia de sus ideas educativas en el origen y desarrollo de una nueva concepción educativa en España en un proceso de larga duración incardinado en el contexto educativo de la Guerra Fría y de la Teoría de la Modernización.

En esa misma línea de entrever nuevos enfoques historiográficos en el estudio de la LGE, se ubica el trabajo de Francisca Comas Rubí y Bernat Sureda García -«La Ley General de Educación a través de las imágenes»- en el que muestran las distintas y contradictorias representaciones discursivas que genera el uso de la fotografía pública y la privada, fruto, como señalan los autores, "de la compleja realidad en la que se gestó y aplicó esta ambiciosa reforma educativa».

Participando de los criterios señalados y a modo de cierre de un propósito esperanzador e ilusionado, como fue el que propició la LGE, el texto de Patricia Delgado Granados - «La Ley General de Educación en la memoria: del reconocimiento a la negación»- ahonda en las polémicas que provoca la Ley, relatando los enfrentamientos que desde un primer momento acosan sus innovaciones reformistas y analizando algunos de los elementos que acabaron por echar la ley en el olvido y negarle un lugar en la memoria colectiva. 
En un monográfico que una revista -cuya cabecera, además, reza Historia y Memoria de la Educación- dedica a la LGE a los cincuenta años de su promulgación, importan los testimonios de personas que en su día y desde sus particulares desempeños profesionales asistieron a su implantación y desarrollo. Corrobora este interés la frecuencia con la que aparecen en muchos trabajos ideas y planteamientos a menudo próximos al deber ser o a la teoría; pareció, pues, conveniente recabar vivencias directamente vinculadas a la realidad, a lo que fue de hecho y en el día a día la reforma de los 70 .

Aunque cincuenta años son muchos para evocar con nitidez lo vivido, sin embargo, las respuestas no han defraudado. Trasluce en ellas no solo la información oportuna sino también la generosidad con la que personas jóvenes se volcaron en la tarea de servir a la educación y mejorarla. A menudo se evidencia que estamos ante un primer amor profesional, con el arrojo, la determinación y la entrega de quien no regatea trabajo, dedicación, inteligencia, esfuerzo, sencillamente, lo mejor de sí mismo. Se tiene la sensación de estar ante la vida, ante sus alientos y sus pálpitos. También aparece, cómo no, la decepción, la comprobación de que no se puede llevar a la práctica lo que prescribe una ley más ambiciosa que realista; e incluso nos atestiguan los obstáculos y dificultades que provenían de quienes debiendo apoyar la mejora de la educación, preferían la comodidad de transitar por caminos ya trillados, la rutina y la aplicación mecánica de normas y reglamentos a pesar de que chocasen con las necesidades reales de la educación del alumnado. Y, con frecuencia, nos encontramos con rasgos que describen la personalidad de sus autores.

Así, pues, siguiendo el mismo criterio de avanzar desde una perspectiva macro a otra micro, quisimos conocer las vivencias de quienes vivieron la reforma desde la administración general del Estado -Manuel de Puelles Benítez nos las comparte en su texto «Mi experiencia con la Ley General de Educación»- y en la administración periférica sobre la que Antonio Viñao comunica su experiencia en «La Ley General de Educación y la reforma de 1970. Una visión personal desde la administración educativa periférica».

De su paso por la Inspección de Primera Enseñanza en ese tiempo, relata su vivencia personal Marc Antoni Adell Cueva en «La Ley General 
de Educación de 1970, cincuenta años de recuerdos». Y desde el magisterio primario nos han legado su testimonio tres maestros, dos que entonces desempeñaban su profesión en escuelas rurales -Alicia López Pardo que lo transmite en «Breve memoria de una maestra rural en tiempos de la EGB» y José María Rozada Martínez, que lo hace en «La Ley General de Educación y la profesionalidad de un docente»-, y un tercero, que ejercía en una cooperativa escolar, Alejandro Tiana Ferrer, quien comparte su experiencia en «Mis años en EGB (1974-1980)».

Seguro que, en estos testimonios, que constituyen un diverso muestrario de diferentes puestos de trabajo en educación, no están todos los que son, pero sí son todos los que están. Tenemos la convicción de que han enriquecido particularmente la sección monográfica de este número de la revista Historia y Memoria de la Educación. A todos ellos les agradecemos su disponibilidad y su generosidad.

\section{REFERENCIAS}

Cabrera Montoya, Blas. «Políticas educativas en clave histórica: La LOGSE de 1990 frente a la LGE de 1970». Tempora 10 (2007): 147-181.

Chamorro Fernández, M. Inés. «Bibliografía sobre la Ley General de Educación de 1970». Revista de Educación n. ${ }^{\circ}$ ext. «La Ley General de Educación veinte años después» (1992): 377-438.

Díez Hochleitner, Ricardo. «Ante la nueva reforma de la Educación». Entrevista. Plantel. Revista de la Escuela Universitaria del Profesorado de Ciudad Real 1 (1989): 22-27.

Fernández de Castro, Ignacio. Reforma educativa y desarrollo capitalista. Informe crítico de la Ley de Educación. Madrid: EDICUSA, 1973.

Gimeno Sacristán, José. La educación que he vivido, por la que trabajo y sigo comprometido. Discurso del nuevo Doctor Honoris Causa Don José Gimeno Sacristán. Málaga: Universidad de Málaga, 2011.

González Gómez, Sara y Xavier Motilla Salas. «Iconografía de la modernización educativa en España en el contexto de la Ley General de Educación de 1970». Historia y Memoria de la Educación 8 (2018): 449-487.

Ministerio de Educación y Ciencia. Libro Blanco para la Reforma del Sistema Educativo. Madrid: MEC, 1989.

Sánchez Tortosa, José. El culto pedagógico. Crítica del populismo educativo. Madrid: Ediciones Akal, 2018. 
Tiana Ferrer, Alejandro. «La Ley General de Educación, veinte años después. Elementos para una revisión». Revista de Educación n. ${ }^{\circ}$ ext. «La Ley General de Educación veinte años después» (1992): 7-10.

Tröhler, Daniel. «School Legislation, Mass Schooling, and Historiography». En School Acts and the Rise of Mass Schooling, editado por J. Westberg, L. Boser y I. Brühwiler, 349-372. Palgrave: Macmillan, Cham, 2019.

Villar Palasí, José Luis. «Discurso del ministro de Educación y Ciencia informando a la Comisión de Educación de las Cortes sobre la aplicación de la Ley General de Educación». Boletín oficial de las Cortes Españolas. Diario de las sesiones de comisiones. Comisión de Educación y Ciencia. Apéndice núm. 10 (14 febrero 1972): 2-12. 